\title{
The Forecasting of Groundwater Fluctuations using Time Series Analysis and Combination of Data-Driven Models
}

\author{
Amirhossein Najafabadipour ${ }^{1}$, Gholamreza Kamali ${ }^{1}$, and Hossein Nezamabadi-pour ${ }^{1}$ \\ ${ }^{1}$ Shahid Bahonar University Faculty of Engineering
}

March 29, 2021

\begin{abstract}
The Forecasting of Groundwater Fluctuations is a useful tool for managing groundwater resources in the mining area. Water resources management requires identifying potential periods for groundwater drainage to prevent groundwater from entering the mine pit and imposing high costs. In this research, Auto-Regressive Integrated Moving Average (ARIMA) and Holt-Winters Exponential Smoothing (HWES) data-driven models were used for short-term modeling of the groundwater fluctuations in a piezometer around the Gohar Zamin Iron Ore Mine. For this purpose, 250 non-seasonal groundwater fluctuations data in the period 22-Nov-2018 to 29-Jul-2019, 200 data for modeling, and 50 data for prediction were used. To take advantage of all the features of the two developed models, the predictions are combined with different methods and specific weights. The results show better accuracy for the ARIMA method between the two short-term forecasts, while the HWES method requires less time for modeling. Also, among all the predictions made, the highest accuracy for the combined least-squares method is for forecasting the groundwater fluctuations in the short-term. All the forecasts show a decrease in the groundwater fluctuations, indicating pumping wells around the Gohar Zamin Iron Ore Mine area.
\end{abstract}

\section{Hosted file}

Main Documents.pdf available at https://authorea.com/users/404563/articles/515725-theforecasting-of-groundwater-fluctuations-using-time-series-analysis-and-combination-ofdata-driven-models

\section{Hosted file}

Pictures.pdf available at https://authorea.com/users/404563/articles/515725-the-forecastingof-groundwater-fluctuations-using-time-series-analysis-and-combination-of-data-drivenmodels

\section{Hosted file}

Tables.pdf available at https://authorea.com/users/404563/articles/515725-the-forecastingof-groundwater-fluctuations-using-time-series-analysis-and-combination-of-data-drivenmodels 